\title{
UMA ANÁLISE SEMÂNTICA E PRAGMÁTICA DOS DIMINUTIVOS NA LEGENDAGEM DO FILME CENTRAL DO BRASIL PARA O INGLÊS
}

\author{
A SEMANTIC AND PRAGMATIC ANALYSIS OF DIMINUTIVES IN THE \\ ENGLISH-LANGUAGE SUBTITLE OF THE PORTUGUESE-LANGUAGE FILM \\ CENTRAL DO BRASIL
}

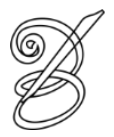 \\ Chunyuan WANG \\ Pontifícia Universidade Católica do Rio Grande do Sul \\ Escola de Humanidades \\ Programa de Pós-Graduação em Letras \\ Porto Alegre, Rio Grande do Sul, Brasil \\ orcid.org/0000-0002-2875-3069 \\ chunyuan.wang@edu.pucrs.br
}

\begin{abstract}
Resumo: Este trabalho tem por objetivo analisar as traduções, do português do Brasil para o inglês, dos diminutivos presentes no filme Central do Brasil, a fim de aferir a adequação das estratégias de tradução utilizadas. Utilizam-se como referencial teórico os estudos de Santos (2001), Schneider (2003), Adams (2001), Armelin (2011) e Chaves (2006) para apresentar uma breve descrição da formação do diminutivo tanto no português quanto no inglês do ponto de vista morfossintático. A partir dessa descrição, introduzem-se as dimensões semântica e pragmática de diminutivos segundo os estudos de Turunen (2008, 2009) e Alves (2006). Após a conclusão dessas duas etapas, uma análise das legendas em inglês foi realizada levando-se em consideração essas duas dimensões. Os resultados mostram que nem todos os diminutivos presentes no filme foram traduzidos de forma correta ou foram traduzidos de modo incompleto. A maior dificuldade é traduzir o tom, ou seja, a dimensão pragmática. Há simetrias completas das duas dimensões para apenas algumas categorias de diminutivos entre o português e o inglês. Conclui-se que, por um lado, é necessário adotar outras estratégias que não sejam as de uso de diminutivos para a tradução, devido à ausência de simetrias completas dessas dimensões; por outro, é necessário o tradutor dominar conhecimentos de diminutivos tanto em português como em inglês e encontrar as simetrias completas possíveis das duas dimensões semântica e pragmática para as categorias de diminutivos possíveis entre o português e o inglês para uma tradução mais adequada.
\end{abstract}

Palavras-chave: Tradução de diminutivos. Simetria. Estratégias. Morfossintaxe. Semântica e pragmática.

Abstract: This paper aims to analyze the Portuguese-English translation of diminutives in the film Central do Brasil in order to assess the adequacy of the translation strategies applied. Drawing on Santos (2001), Schneider (2003), Adams (2001), Armelin (2011) and Chaves (2006), it provides a brief description of how diminutives are formed in both Portuguese and English from a morphosyntactic perspective. Based on this description, it introduces the semantic and pragmatic dimensions of diminutives according to Turunen $(2008,2009)$ and Alves (2006). It uses these two dimensions to analyze the English-language subtitles in the film. The result shows that not all diminutives are translated correctly or completely, and the greatest difficulty lies in translating the tone, i.e., the pragmatic dimension. In fact, complete symmetry of both dimensions across Portuguese and English only exists in a few categories of diminutives. As a result, on the one hand, it is necessary to adopt translation strategies other than equivalent diminutives in some instances; on the other hand, the translator needs to master the diminutives in both Portuguese and English to find those diminutives that are completely symmetrical on both semantic and pragmatic dimensions.

Keywords: Translation of diminutives. Symmetry. Strategies. Morphosyntax. Semantics and pragmatics. 


\section{Introdução}

raduzir os diminutivos em português significa traduzir a dimensão semântica deles,
uma vez que o sentido de tamanho e quantidade da entidade referida é reduzido.
Geralmente, as categorias que apresentam essa dimensão em português são os substantivos e os adjetivos, sendo preferidos, na tradução para o inglês, adjetivos como little, que pode expressar a redução de quantidade, e small, que pode indicar o tamanho reduzido.

A tradução dos diminutivos em português também implica traduzir a dimensão pragmática deles, na medida em que muitas vezes os diminutivos expressam valores extralinguísticos, como afetividade e ironia dos locutores. No exemplo, "Aquele carinha ali, de barba", o que significa "carinha"? Cara pequeno? Cara baixo? Pode-se perceber que não é suficiente apenas traduzir o significado semântico para expressar o sentido completo envolvido na frase. Para expressar melhor o sentido da frase, o tradutor pode, por exemplo, evidenciar o tom que o locutor quer expressar ou pode tentar traduzir utilizando diminutivos em inglês para expressar o sentido da frase em português. Assim, o objetivo deste trabalho é discutir e investigar quais as estratégias e/ou traduções mais adequadas para a tradução de diminutivos em português por meio da análise das dimensões semântica e pragmática desses diminutivos.

As falas do filme Central do Brasil são repletas de diminutivos, e seu uso pode indicar não só tamanho e quantidade, mas também ironia, afetividade, avaliação etc. Devido ao fato de o português ser uma língua latina e o inglês ser um idioma anglo-saxônico, os diminutivos são formados de maneiras distintas e, muitas vezes, não possuem um equivalente direto, exigindo assim muita atenção e uso de diferentes estratégias por parte do tradutor. As regras de formação e de uso do diminutivo tanto na língua-fonte como na língua-alvo são essenciais para que o tradutor consiga produzir um texto-alvo adequado.

Para descrever a análise realizada, este artigo foi dividido em duas seções. A primeira seção é subdividida em duas subseções. A subseção 1.1 explica a formação dos diminutivos no português e no inglês em termos de morfossintaxe, tendo como referência teórica os estudos de Santos (2001), Armelin (2011), Schneider (2003), Adams (2001) e Chaves (2006). A subseção 1.2 trata das dimensões semântica e pragmática dos diminutivos no português, de acordo com os estudos de Turunen $(2008,2009)$ e Alves (2006). A segunda seção, por sua vez, é também dividida em duas subseções. A subseção 2.1 levanta todas as ocorrências de diminutivos apresentadas no filme Central do Brasil. A subseção 2.2 apresenta uma análise desses diminutivos e suas respectivas traduções ${ }^{1}$ para o inglês, com os principais problemas encontrados. A partir dessa análise, algumas sugestões e/ou estratégias de tradução mais 
adequadas são dadas.

\section{Revisão e fundamentação teórica}

O uso de diminutivos é um fenômeno linguístico interessante nas línguas humanas, inclusive, na língua portuguesa, a qual mostra um uso muito mais frequente em comparação ao no inglês e ao chinês mandarim. Devido à sua alta frequência de uso e sua propriedade universal cross-linguistically, muitos estudos foram feitos e estão sendo feitos, a partir de perspectivas teóricas diferentes.

Quanto aos estudos monolíngues de diminutivos no português, sob a perspectiva sincrônica, Barbosa (2012) investigou, baseando-se na Sociolinguística Variacionista e na Fonologia de Uso, de Bybee (1985), se as formações X-inho e X-zinho são oriundas de um único sufixo diminutivo ou de dois processos distintos a partir da análise de alternância do diminutivo -inho/-zinho. Por sua vez, Rodrigues (2015) fez uma análise variacionista sobre o uso dos diminutivos com sufixos de -inho/-im e -zinho/-zim nas cidades de Mariana e Piranga do estado de Minas Gerais, com os objetivos de investigar as suas condições de uso, distribuição, origem e estratificação social e linguística. Sob a perspectiva diacrônica, Abreu (2012) analisou o estatuto prosódico das aumentativas e diminutivas no português arcaico do século XIII como formas simples ou compostas, com base na observação dos fenômenos prosódicos provocados pelo processo morfofonológico da adjunção dos sufixos -inno e variações para o diminutivo e -on(a) para o aumentativo. Por sua vez, Santana (2017) estudou a forma, funcionamento e significação dos diminutivos em português do século XIII ao XX.

Em relação aos estudos de tradução de diminutivos, Turunen (2006) analisou a tradução em francês dos diminutivos com sufixo -inho presentes no livro Dona Flor e seus dois maridos, de Jorge Amado (1966), a fim de revelar os diversos valores semânticos desses diminutivos e as estratégias de tradução utilizadas. Segundo Turunen (2006), o tradutor precisa recorrer a várias estratégias de natureza semântica e sintática para traduzir os valores transmitidos por um único diminutivo. Por sua vez, Basso e Petry (2013) analisaram o uso dos diminutivos na tradução da história em quadrinhos Les aventures de Tintin: Tintin en Amérique, do francês para o português do Brasil. Basso e Petry propuseram uma organização semântico-pragmática dos diminutivos no português brasileiro em três categorias, a saber, interpretação composicional do diminutivo, interpretação não composicional do diminutivo e interpretação não estritamente composicional do diminutivo. A interpretação composicional expressa exclusivamente a ideia de tamanho; a interpretação não composicional está ligada às novas palavras diminutivas e seus 
significados não podem ser compreendidos por meio das partes que o diminutivo; e a interpretação não estritamente composicional está ligada aos diminutivos que veiculam a ideia de expressividade, afetividade, apreciação, intensificação, ironia e pejoratividade. Vale notar que a classificação das três categorias de uso do diminutivo no português brasileiro de Basso e Petry (2013) é muito semelhante à dos diminutivos com sufixo -inho de Alves (2006), na qual esse trabalho se baseia.

Diferente das análises sobre tradução dos diminutivos entre português e francês de Turunen (2006) e de Basso e Petry (2013), este trabalho analisa a tradução em inglês dos diminutivos presentes no filme Central do Brasil, a partir de uma perspectiva semântica e pragmática dos diminutivos. O trabalho tem relevância ao estudar a tradução de diminutivos na legendagem sob os dois aspectos. Em primeiro lugar, o português e o inglês são línguas de famílias bem distintas; para chegar a uma tradução mais adequada, o tradutor precisa não só dominar conhecimentos de diminutivos nas duas línguas, mas também adotar outras estratégias que não sejam as de uso de diminutivos. Em segundo, este trabalho aponta um problema de espaço na tradução de legendagem, que talvez não se encontre na tradução de obras literárias em papel, na medida em que o tradutor pode ainda recorrer às estratégias de natureza semântica e sintática para traduzir os valores transmitidos por um único diminutivo nessas obras (TURUNEN, 2006).

\subsection{Morfossintaxe do diminutivo}

\subsubsection{Morfossintaxe do diminutivo no inglês}

O diminutivo no inglês é formado principalmente de duas maneiras, ora por meio da adição de sufixos (-een, -ie) após a palavra-base , de acordo com Schneider (2003, p. 2), o que é semelhante com a formação do diminutivo no português (-inho, -zinho), ora por meio da adição de adjetivos (tiny, little) ou advérbios (too) na frente da palavra-base para expressar a sua redução (DRESSLER; BARBARESI, 1994, p. 114).

Schneider (2003) divide os sufixos de diminutivos no inglês contemporâneo em quatorze tipos, como mostra o Quadro 1 . O primeiro grupo, -ie, -ette e -let, corresponde àqueles considerados mais produtivos; e o quarto grupo, $-s,-e r,-o,-a, e-l e$, compreende aqueles que geralmente expressam familiaridade e atitude afetiva ou avaliativa do locutor ou interlocutor em vez de pequenez, o que representa bem a dimensão pragmática. Os outros tipos são raramente adotados.

Quadro 1 - Sufixos de diminutivos no inglês

WANG, Chunyuan. Uma análise semântica e pragmática dos diminutivos na legendagem do filme Central do Brasil para o inglês. Belas Infiéis, Brasília, v. 9, n. 4, p. 229-247, jul./set., 2020. e-ISSN: 2316-6614.

DOI: $10.26512 /$ belasinfieis.v9.n4.2020.26465 


\begin{tabular}{|l|l|}
\hline Sufixos mais produtivos & - -ie, - ette $e$-let \\
\hline Sufixos originalmente germânicos & -kin $e$-ling \\
\hline Sufixo originalmente inglês irlandês & $-e e n$ \\
\hline Sufixos de "marcadores de familiaridade" & $-s,-e r,-o,-a, e-l e$ \\
\hline Sufixos raramente mencionados na literatura & - poo, - pop $e-p e g$ \\
\hline
\end{tabular}

Fonte: Schneider (2003, p. 342).

Exibir exaustivamente as classificações e exemplos dos sufixos diminutivos no inglês foge da intenção deste artigo. O leitor interessado pode consultar o estudo de Schneider (2003) para saber mais sobre a classificação dos sufixos diminutivos em inglês, bem como os estudos de Schneider (2003) e Adams (2001) para ler as explicações e exemplos dessas classificações. Segundo Santos (2001, p. 75): “[c]ontudo, o inglês não faz uso frequente desses sufixos diminutivos apesar de possui-los.”.

\subsubsection{Morfossintaxe do diminutivo no português}

Antes de descrever a formação do diminutivo em português, é necessário referir-se às formações do diminutivo nas línguas clássicas - no caso, o grego e o latim, com as quais o português tem uma relação estreita. Segundo a classificação de Santos (2001), os sufixos de diminutivos de substantivos no grego clássico são aqueles dispostos no Quadro 2.

Quadro 2 - Sufixos de diminutivos de substantivos no grego clássico

\begin{tabular}{|c|c|c|}
\hline Sufixo & Substantivo-base & Diminutivo \\
\hline$-\mathrm{lov}$ & o $\lambda \kappa \alpha \sigma$ (barco) & o $\lambda \kappa \alpha \delta$ เov (barquinho) \\
\hline$-l \delta l o v$ & 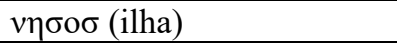 & 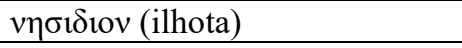 \\
\hline$-\alpha \rho i o v$ & $\zeta \omega o v($ animal) & $\zeta \omega \alpha \rho ı v$ (animalzinho) \\
\hline$-l \sigma \kappa o \sigma$ & $\alpha \sigma \tau \varepsilon \rho$ (estrela) & $\alpha \sigma \tau \varepsilon \rho ı \sigma \kappa о \sigma$ (estrelinha) \\
\hline$-v \delta \rho l o v$ & $\mu \varepsilon \lambda o \sigma$ (canção) & $\mu \varepsilon \lambda v \delta \rho ı v$ (cançoneta) \\
\hline$-v \lambda \lambda l o v$ & $\varepsilon ı \delta \circ \sigma$ (imagem) & $\varepsilon 1 \delta v \lambda \lambda$ lov (figurinha, quadrinho) \\
\hline
\end{tabular}

Fonte: Santos (2001, p. 71).

Por sua vez, os sufixos de diminutivos de substantivos que se usavam, mais frequentemente e de forma mais produtiva, no latim clássico são aqueles apresentados no Quadro 3. 
Quadro 3 - Sufixos de diminutivos de substantivos mais usados no latim clássico

\begin{tabular}{|l|l|l|}
\hline \multicolumn{1}{|c|}{ Sufixo } & \multicolumn{1}{|c|}{ Substantivo-base } & \multicolumn{1}{c|}{ Diminutivo } \\
\hline -ulus & puer (criança) & puerulus (-criancinha) \\
\hline -culus & flos (flor) & flosculus (-florzinha) \\
\hline -ellus & liber (livro) & libellus (-livrinho) \\
\hline -illus & - & - \\
\hline -unculus & homo (homem) & homunculus (homem pequeno) \\
\hline
\end{tabular}

Fonte: adaptado de Santos (2001, p. 72).

O português moderno segue o mesmo mecanismo de formação de diminutivos do grego e do latim, por meio do acréscimo dos sufixos diminutivos, dos quais -inho/-zinho são mais produtivos. Segundo Armelin (2011), esses sufixos de diminutivos podem ser anexados a diferentes categorias sintáticas, como mostra o Quadro 4.

Quadro 4 - Diminutivos nas diferentes categorias sintáticas

\begin{tabular}{|l|l|l|}
\hline \multicolumn{1}{|c|}{ Categoria sintática } & \multicolumn{1}{c|}{ Palavra-base } & \multicolumn{1}{c|}{ Diminutivo } \\
\hline Substantivo & menino & menininho \\
\hline Adjetivo & bonito & bonitinho \\
\hline Advérbio & lento & lentinho \\
\hline Forma gerundiva & correndo & correndinho \\
\hline
\end{tabular}

Fonte: adaptado de Armelin (2011, p. 5).

O português possui uma variedade de sufixos diminutivos, que podem ser resumidos no Quadro 5, conforme Chaves (2006). Dentro desses sufixos diminutivos, -inho é mais usado na língua falada, conforme afirma Chaves (2006, p. 38).

Quadro 5 - Diferentes tipos de diminutivos no português

\begin{tabular}{|c|c|c|c|}
\hline Sufixo & Diminutivo & Sufixo & Diminutivo \\
\hline $\begin{array}{l}\text {-zinho/a } \\
\text {-ino/a } \\
\text {-im }\end{array}$ & $\begin{array}{l}\text { cãozinho } \\
\text { cravina } \\
\text { espadim }\end{array}$ & $\begin{array}{l}\text {-elho/a } \\
\text { - ejo } \\
\text {-ilho/a }\end{array}$ & $\begin{array}{c}\text { rapazelho } \\
\text { animalejo } \\
\text { tropilha }\end{array}$ \\
\hline $\begin{array}{l}\text {-acho/a } \\
\text {-icho/a } \\
\text {-ucho/a }\end{array}$ & $\begin{array}{l}\text { riacho } \\
\text { barbicha } \\
\text { casucha }\end{array}$ & $\begin{array}{l}\text {-ete } \\
\text {-eto/a } \\
\text {-ito/a }\end{array}$ & $\begin{array}{l}\text { lembrete } \\
\text { saleta } \\
\text { casita }\end{array}$ \\
\hline -ebre & casebre & $\begin{array}{l}-z i t o / a \\
-o t e / a\end{array}$ & $\begin{array}{l}\text { florzita } \\
\text { velhote }\end{array}$ \\
\hline $\begin{array}{l}-e c o / a \\
-i c o / a\end{array}$ & $\begin{array}{l}\text { livreco } \\
\text { burrico }\end{array}$ & $\begin{array}{l}\text {-isco/a } \\
\text { - usco/a }\end{array}$ & $\begin{array}{l}\text { chuvisco } \\
\text { velhusco }\end{array}$ \\
\hline -ela & ruela & -ola & rapazola \\
\hline
\end{tabular}

Fonte: Chaves (2006, p. 41).

\subsection{Semântica e pragmática dos diminutivos no português}

Após a descrição dos aspectos morfológicos, apresentam-se as dimensões semântica e pragmática dos diminutivos no português, ressaltando-se que a dimensão pragmática mostra 
uma complexidade muito maior que a dimensão semântica, em termos de expressividade (TURUNEN, 2008, p. 9). Quanto aos estudos de dimensões semântica e pragmática, Basílio (2004), Alves (2006) e Rocha (2003) são considerados relevantes por identificarem os valores semânticos e as funções pragmáticas dos diminutivos, segundo Turunen (2008, 2009). Nos próximos parágrafos, apresenta-se o estudo de Alves (2006). Os dados da seção 2 deste trabalho são analisados a partir desse último autor.

Alves (2006) tem como base a teoria da Gramática Funcional do Discurso para explorar as diversas funções dos diminutivos formados em -inho na língua portuguesa. A autora divide o -inho em três categorias: (i) -inhol representa diminutivos que expressam propriedade inerente do objeto ou qualidade apresentando um valor semântico; (ii) -inho2, por sua vez, indica uma avaliação do falante perante a entidade referida, expressando um valor pragmático; (iii) -inho3 é parecido com -inho 2 , mas apresenta uma avaliação do falante em relação à comunicação ou ao ouvinte. A autora resume que ambos os $-i n h o_{2} \mathrm{e}-$-inho $_{3}$ apresentam propriedade atribuída, o que demonstra a dimensão pragmática do diminutivo. A fim de explicar melhor os três “morfemas", a autora cria critérios e exemplifica conforme mostrado no Quadro 6.

Quadro 6 - Classificação e exemplos

\begin{tabular}{|l|l|}
\hline \multicolumn{1}{|c|}{ Palavra-base } & \multicolumn{1}{c|}{ Diminutivo } \\
\hline peixe & peixinho \\
\hline casa & casinha \\
\hline nova & novinha \\
\hline sobressalto & Sobressaltozinho \\
couve-flor & ? couve-florzinha, \\
pé-de-moleque & $-? ?$ pé-de-molequinho \\
\hline João & Joãozinho \\
meu bem & meu benzinho \\
\hline um & unzinho \\
tudo & tudinho \\
cedo & cedinho \\
\hline tchau & tchauzinho \\
obrigada & obrigadinha \\
um minuto & um minutinho \\
\hline
\end{tabular}

Fonte: adaptado de Alves (2006, p. 697).

De acordo com Alves (2006), o primeiro sufixo -inho 1 funcionaria como um operador de intensificação que somente se aplicaria no nível de "palavra", ou seja, somente no nível semântico. Devido a essa propridade, sua função sintática seria: ou nominal, como mostra o primeiro grupo "peixe-peixinho" do Quadro 6, a qual apresenta um conceito concreto reduzido que está no nível semântico da palavra: ou adjetival, como mostra o terceiro grupo "novanovinha" do Quadro 6, a qual apresenta a qualidade reduzida. Ainda segundo Alves (2006), em 
geral, esse tipo de diminutivo apresenta propridades inerentes a objetos, como, por exemplo, tamanho reduzido, quantidade reduzida e intensidade reduzida, além de também apresentar qualidades.

No entanto, o segundo e terceiro sufixos -inho 2 e-inhos seriam operadores cuja função vai muito além do sentido semântico que está no nível de palavra, ou seja, esses diminutivos funcionariam mais como operadores no nível pragmático, ou seja, no nível do Ato do Discurso propiramente dito. Nesse caso, eles buscam estabelecer sentido mais pragmático e, consequentemente, o valor semântico seria bem reduzido. Veja-se a divisão dos três tipos de sufixos no Quadro 7.

Quadro 7 - Expressão representacional e expressão de ilocução

\begin{tabular}{|c|c|c|}
\hline- inho $_{1}$ & \multirow{7}{*}{ vs. } & - inho $_{2},-$-inho $_{3}$ \\
\hline propriedade inerente & & propriedade atribuída \\
\hline $\begin{array}{l}\text { valor semântico: } \\
\text { operador de intensificação }\end{array}$ & & $\begin{array}{l}\text { valor pragmático: } \\
\text { operadores de subjetividade, afetividade, } \\
\text { avaliação, mitigação, crítica... }\end{array}$ \\
\hline $\begin{array}{l}\text { operador no nível da 'palavra' (nível } \\
\text { representacional) }\end{array}$ & & $\begin{array}{l}\text { operador no nível do Ato do Discurso (nível } \\
\text { interpessoal) }\end{array}$ \\
\hline categoria de base: $\mathrm{N}, \mathrm{Adj}$ & & sem restrição de categoria de base; enunciados \\
\hline $\begin{array}{l}\text { função: modificação de núcleos, substantivos e } \\
\text { adjetivais }\end{array}$ & & $\begin{array}{l}\text { função: estratégias comunicativas, por meio de } \\
\text { modificação interpessoal }\end{array}$ \\
\hline entonação neutra & & entonação marcada \\
\hline
\end{tabular}

Fonte: Alves (2006, p. 698-699).

Os sufixos -inhor e -inho 3 se diferenciam de acordo com a avaliação do falante em relação à entidade referida (sufixo -inhos) e à situação comunicativa ou ao ouvinte (sufixo inho3), conforme exibido no Quadro 8.

Quadro 8 - Subdivisão da expressão de ilocução

\begin{tabular}{|l|l|l|}
\hline \multicolumn{1}{|c|}{-inho2 } & \multirow{2}{*}{ vs. } & \multicolumn{1}{c|}{-inho3 } \\
\cline { 1 - 1 } $\begin{array}{l}\text { avaliação / julgamento do falante frente à } \\
\text { entidade: tamanho, valor, afetividade, desprezo }\end{array}$ & $\begin{array}{l}\text { avaliação / julgamento do falante frente à } \\
\text { situação comunicativa e ao ouvinte: } \\
\text { ironia, polidez, mitigação e outros }\end{array}$ \\
\hline
\end{tabular}

Fonte: Alves (2006, p. 699).

Por exemplo, o caso do quinto grupo "João - Joãozinho e meu bem - meu benzinho" do Quadro 6 expressa uma avaliação de afetividade do falante perante o ouvinte (entidade referida), ou seja, "ser querido por ser pequeno" (ALVES, 2006, p. 699). No entanto, o caso do sétimo grupo "tchau - tchauzinho, obrigada - obrigadinha, um minuto - um minutinho" do 
mesmo quadro expressa também a posição de locutor e de interlocutor, com intenção de ironizar ou ser polido, além de expressar uma avaliação da entidade envolvida perante a interação (ALVES, 2006).

\section{Análise}

\subsection{Levantamento das ocorrências de diminutivos no filme Central do Brasil}

Nas falas do filme Central do Brasil, 25 ocorrências de diminutivos, como mostra o Quadro 9. Segundo a classificação de Alves (2006), os diminutivos com sufixo -inho 1 podem expressar propriedade inerente do objeto ou qualidade, apresentando um valor semântico; os diminutivos com sufixo -inho2, por sua vez, podem indicar uma avaliação do falante perante a entidade referida, expressando um valor pragmático; e os diminutivos com sufixo -inho3 podem apresentar uma avaliação do falante em relação à comunicação ou ao ouvinte. Vale notar que um diminutivo pode mostrar tanto a dimensão semântica como a dimensão pragmática dependendo do contexto no qual é apresentado. Por exemplo, (1) demonstra apenas a dimensão semântica de quantidade reduzida do diminutivo "pouquinho", enquanto (2) e (3) apresentam fortemente a dimensão pragmática do mesmo diminutivo, que é um tom, uma avaliação do falante em relação à entidade referida (dinheiro) e ao ouvinte ou à situação comunicativa.

(1) Deixa um pouquinho ${ }_{1}$ de dinheiro para eu comer

(2) Olhe o que comprei com o pouquinho 2 dinheiro que tinha.

(3) Dava pra botar o menino um pouquinhoz no volante. Dava? 
Quadro 9-Ocorrências de diminutivos no Central do Brasil

\begin{tabular}{|c|c|c|c|}
\hline Diminutivo & Ocorrência & Sufixo & Valor \\
\hline Dinheirinho $_{1}$ & \multirow{2}{*}{2} & $-i n h o_{1}$ & Semântico \\
\hline Dinheirinho $_{2}$ & & inho $_{2}$ & Pragmático \\
\hline Filhinho & 2 & $\mathrm{inho}_{2}$ & Pragmático \\
\hline Palavrinha & 1 & $\mathrm{inho}_{2}$ & Pragmático \\
\hline Linguinha & 1 & $\mathrm{inho}_{2}$ & Pragmático \\
\hline Grandinho & 1 & - -inho $_{3}$ & Pragmático \\
\hline Lindinhas & 1 & inho $_{3}$ & Pragmático \\
\hline Minutinho & 1 & - -inho $_{3}$ & Pragmático \\
\hline Pouquinho (N) & \multirow{3}{*}{3} & - inhol $_{1}$ & Semântico \\
\hline Pouquinho (Adj) & & $-\mathrm{inho}_{2}$ & Pragmático \\
\hline Pouquinho (Adv) & & - inho $_{3}$ & Pragmático \\
\hline Carinha & 1 & - -inho $_{3}$ & Pragmático \\
\hline Coisinha & 1 & $-i n h o_{1}$ & Semântico \\
\hline Pequeninho & 1 & - inho $_{3}$ & Pragmático \\
\hline Todinha & 2 & - -inho $_{3}$ & Pragmático \\
\hline Cafézinho & 1 & inho $_{2}$ & Pragmático \\
\hline Casinha & 1 & $-i n h o_{1}$ & Semântico \\
\hline Bilhetinho & 1 & - inhol $_{1}$ & Semântico \\
\hline Criseldinha & 1 & - inho $_{2}$ & Pragmático \\
\hline Mocinha & 1 & $-\mathrm{inho}_{3}$ & Pragmático \\
\hline Jeitosinha & 1 & - inho $_{3}$ & Pragmático \\
\hline Menininha & 1 & inho $_{3}$ & Pragmático \\
\hline Retratinho & 1 & $-i n h o_{1}$ & Semântico \\
\hline
\end{tabular}

Fonte: elaboração própria.

\subsection{Análise das ocorrências}

\subsubsection{Diminutivo -inho 1}

Vale relembrar que o sufixo -inhol seria um intensificador e se operaria apenas no nível de palavra, ou seja, somente no nível semântico, com um tom neutro. Ele apresenta somente propridades inerentes a objetos, como, por exemplo, tamanho reduzido, quantidade reduzida e intensidade reduzida, assim como qualidades, de uma categoria de base dada (substantivo ou adjetivo). Os Quadros 10 e 11 mostram as dimensões semânticas de quantidade reduzida e tamanho reduzido das ocorrências de diminutivos no filme Central do Brasil, respectivamente.

Quadro 10 - Diminutivos que indicam quantidade reduzida

\begin{tabular}{|c|c|c|c|}
\hline \multicolumn{2}{|l|}{ Tempo } & Português & Inglês \\
\hline $\begin{array}{l}\text { 1. } 00: 17: 57,396 \\
00: 18: 02,299\end{array}$ & $-->$ & $\begin{array}{l}\text {-Estou juntando...dinheirinho }{ }_{1} \text { para } \\
\text { voltar para a escola. }\end{array}$ & -I'm saving up to go back to school. \\
\hline $\begin{array}{l}2 . \quad 00: 37: 00,271 \\
00: 37: 04,173\end{array}$ & $-->$ & $\begin{array}{l}\text {-Deixa um pouquinho } o_{l} \text { de dinheiro para } \\
\text { eu comer. }\end{array}$ & -Just give me a little money to eat. \\
\hline $\begin{array}{l}\text { 3. } \quad 00: 51: 53,296 \\
00: 51: 57,255\end{array}$ & $-->$ & $\begin{array}{l}\text {-E ainda deu para comprar mais uma } \\
\text { coisinha. }\end{array}$ & $\begin{array}{l}\text {-and there was even enough for some } \\
\text { other stuff. }\end{array}$ \\
\hline
\end{tabular}

Fonte: elaboração própria.

WANG, Chunyuan. Uma análise semântica e pragmática dos diminutivos na legendagem do filme Central do Brasil para o inglês. Belas Infiéis, Brasília, v. 9, n. 4, p. 229-247, jul./set., 2020. e-ISSN: 2316-6614.

DOI: 10.26512/belasinfieis.v9.n4.2020.26465 
Nesses exemplos, os diminutivos expressam uma ideia de quantidade reduzida, indicando pouco dinheiro, bem pouco e pouca coisa, respectivamente. No exemplo 1, o tradutor utiliza o phrasal verb "save up", que significa economizar; no entanto, o uso apenas do verbo não especifica a quantidade de dinheiro que é necessária para voltar para a escola. No exemplo 2, o adjetivo a little é adotado, o que expressa bem a ideia de quantidade reduzida. No exemplo 3, por sua vez, é possível perceber que o tradutor opta pelo não uso do diminutivo em inglês para expressar o diminutivo "coisinha" da fala em português.

Quadro 11 - Diminutivos que indicam tamanho reduzido

\begin{tabular}{|c|c|c|c|}
\hline \multicolumn{2}{|l|}{ Tempo } & Português & Inglês \\
\hline $\begin{array}{l}\text { 4. } \quad 01: 10: 16,265 \\
01: 10: 21,225\end{array}$ & $-->$ & $\begin{array}{l}\text {-Ele ganhou uma casinha no sorteio e } \\
\text { vendeu essa aqui. }\end{array}$ & n a house in a raffle and sold \\
\hline $\begin{array}{l}\text { 5. } \quad 01: 18: 17,212 \\
01: 18: 20,181\end{array}$ & $-->$ & $\begin{array}{l}\text {-Eu quero mandar um bilhetinho, } \\
\text { quanto custa? }\end{array}$ & $\begin{array}{l}\text {-I want to send a letter. How much is } \\
\text { it? }\end{array}$ \\
\hline $\begin{array}{l}6 . \quad 01: 43: 53,280 \\
01: 43: 57,239\end{array}$ & $-->$ & $\begin{array}{l}\text {-No dia que quiser lembrar de mim, dá } \\
\text { uma olhada no retratinho que a gente } \\
\text { tirou junto. }\end{array}$ & $\begin{array}{l}\text {-Whenever you want to remember me, } \\
\text { take a look at the small picture we } \\
\text { took together. }\end{array}$ \\
\hline
\end{tabular}

Fonte: elaboração própria.

Nos exemplos do Quadro 11, os diminutivos em português apresentam uma ideia de tamanho reduzido, indicando casa pequena, bilhete pequeno e retrato pequeno, respectivamente. O tradutor não traduziu o tamanho da casa e utiliza apenas a palavra house, talvez porque não tenha notado essa pequenez ou tenha optado por não expressá-la em inglês. Vale ressaltar que o tradutor traduziu bem o sentido do "bilhetinho", que, no contexto do filme, não indica uma mensagem curta, mas sim uma carta, "a letter".

De fato, todos os exemplos mostrados nos Quadros 10 e 11 podem também expressar certa atitude (dimensão pragmática) do falante dependendo do contexto em que são apreesentados, além da dimensão semântica apresentada por eles. Por exemplo, "casinha” pode ser objetivo, sobre tamanho, mas também pode ser afetivo, sobre meu lugar.

\subsubsection{Diminutivo -inhor}

O sufixo -inho 2 é um operador cuja função vai além de expressar valor semântico; pelo contrário, funciona mais como um operador no nível pragmático e expressa uma avaliação ou julgamento do falante, como tamanho, valor, afetividade, desprezo com um tom marcado. Essa avaliação presenta propriedades atribuídas a uma entidade dada, a qual se diferencia da do sufixo -inhos pelo fato de que a segunda mostra uma avaliação em relação à situação 
comunicativa ou ao colocutor com o qual está falando o locutor. Em comparação à restrição de categorias de base (substantivo e adjetivo) para as quais o sufixo -inho ${ }_{1}$ é aplicado, não há essa restrição para o sufixo -inho 2 . No nível pragmático, o valor semântico será bem reduzido em termos de tradução de uma entidade dada. Os Quadros 12 e 13 exibem as dimensões pragmáticas de quantidade reduzida avaliada e de afetividade das ocorrências de diminutivos no filme Central do Brasil, respectivamente.

Quadro 12 - Diminutivos que indicam quantidade reduzida avaliada

\begin{tabular}{|l|l|l|l|}
\hline \multicolumn{1}{|c|}{ Tempo } & \multicolumn{1}{|c|}{ Português } & \multicolumn{1}{c|}{ Inglês } \\
\hline $\begin{array}{l}\text { 7. 00:51:48,291 --> } \\
\text { 00:51:53,251 }\end{array}$ & $\begin{array}{l}\text {-Olhe o que comprei com o pouquinho } 2 \\
\text { dinheiro que tinha. }\end{array}$ & $\begin{array}{l}\text {-You see? I bought the food with the } \\
\text { money that was left over. }\end{array}$ \\
\hline $\begin{array}{l}\text { 8. 00:52:00,303 --> } \\
\text { 00:52:03,204 }\end{array}$ & $\begin{array}{l}\text {-Tinha. Tinha um dinheirinho } 2 . \\
\text {-I had } \text { a little left over... }\end{array}$ \\
\hline
\end{tabular}

Fonte: elaboração própria.

Nesses exemplos, o valor semântico de quantidade reduzida é minimizado, enquanto o valor pragmático de uma avaliação própria do falante de quantidade reduzida em relação ao dinheiro é enfatizado. O diminutivo "dinheirinho2" no exemplo 8 é adotado para expressar uma avaliação do falante, ao passo que é expresso com uma entonação neutra, como pouco dinheiro, no diminutivo "dinheirinho," no exemplo 1. Ao se observar a estratégia que o tradutor utilizou no exemplo 7, aparentemente ele pode ter escolhido por "Money" nesse caso, em vez de "little money", para evitar repetição com a tradução da próxima fala no exemplo 8 , no qual usa " $a$ little" para referir-se à quantidade que não havia expressado anteriormente com apenas a tradução "money". Vale notar que a avaliação do falante em relação à quantidade de dinheiro no exemplo 7 não foi bem traduzida por ter optado por "money", que não carrega nenhuma atitude consigo, enquanto a mesma avaliação foi bem traduzida no exemplo 8 mediante a tradução "a little", que traz certo sabor de atitude do falante.

Quadro 13 - Diminutivos que indicam afetividade

\begin{tabular}{|c|c|c|c|}
\hline \multicolumn{2}{|l|}{ Tempo } & Português & Inglês \\
\hline $\begin{array}{l}9 . \quad 00: 19: 11,336 \\
00: 19: 13,304\end{array}$ & & -Oi, filhinho. & -Hi, son! \\
\hline $\begin{array}{c}00: 19: 55,380 \\
00: 19: 57,348\end{array}$ & $-->$ & -Oi, filhinho. & -Hey, son... \\
\hline $\begin{array}{l}\text { 10. } \quad 00: 49: 32,222 \\
00: 49: 34,190\end{array}$ & $-->$ & -Ei, meninão. Meninão. & -Sonny. Sonny! \\
\hline $\begin{array}{l}\text { 11. } 00: 19: 32,357 \\
00: 19: 36,316\end{array}$ & $-->$ & $\begin{array}{l}\text {-Então quero ter uma palavrinha com a } \\
\text { senhora. }\end{array}$ & -I'd like to speak to you. \\
\hline $\begin{array}{l}\text { 12. } 00: 27: 56,260 \\
00: 27: 59,229\end{array}$ & $-->$ & -Mostra a linguinha para a tia. & -Stick out that little tongue of yours... \\
\hline
\end{tabular}

WANG, Chunyuan. Uma análise semântica e pragmática dos diminutivos na legendagem do filme Central do Brasil para o inglês. Belas Infiéis, Brasília, v. 9, n. 4, p. 229-247, jul./set., 2020. e-ISSN: 2316-6614.

DOI: 10.26512/belasinfieis.v9.n4.2020.26465 


\begin{tabular}{|lc|l|l|}
\hline 13. 00:32:37,275 & $->>$ & -Essas crianças. & -There are some beautiful ones here. \\
00:32:40,244 & & São lindinhas. Olha aqui. & \\
\hline 14. 01:07:39,241 --> & -Já serviu um cafézinho, Dona Violeta? & -Would you like some coffee? \\
$01: 07: 43,200$ & & & \\
\hline 15. 01:18:40,235 & $->$ & -Criselda, Criseldinha. & -Criselda, my Criselda. \\
$01: 18: 45,195$ & & & \\
\hline
\end{tabular}

Fonte: elaboração própria.

Todos os diminutivos do Quadro 13 estão com um tom afetivo e são dificilmente traduzidos, motivo pelo qual se aponta aqui que o inglês não faz uso frequente dos diminutivos como o português. Isso também foi apontado por Santos (2001).

Por isso, o tradutor pode ter optado pela estratégia de deixar sem indicar o diminutivo, respeitando o que pode ser mais comum na língua-alvo, como mostram os exemplos 9, 11, 13, 14 e 15. Os diminutivos "filhinho" no exemplo 9 expressam uma ideia de menino pequeno, menininho com afetividade, o que aparentemente indica que é inadequado serem traduzidos em inglês como "son". É interessante notar que o tradutor adotou "sonny", que é um diminutivo de son que expressa um mesmo sentido de menininho com afetividade, para traduzir "meninão" no exemplo 10. Talvez o tradutor tenha escolhido traduzir assim tendo em consideração a estratégia aplicada nos exemplos 7 e 8: evitar repetição.

Em relação à tradução do diminutivo "Criseldinha" no exemplo 15, "my Criselda" interpreta bem o sentido desse diminutivo. A simetria semântica e pragmática entre o diminutivo "Criseldinha" em português e a expressão "my Criselda" em inglês parece sugerir que pode ser uma estratégia adequada traduzir o nome próprio diminutivo em português utilizando a expressão $m y$ + nome próprio em inglês. Porém, para averiguar essa hipótese, é preciso montar dois corpora: um corpus do uso dessa estratégia por tradutores e um corpus monolíngue sobre a expressão $m y$ + nome próprio em inglês. Tendo em consideração a questão de tempo, essa investigação fica para outra oportunidade. Vale ressaltar que, para chamar alguém afetivamente, o uso do sufixo -ie também pode ser considerado. De acordo com Schneider (2003, p. 87), o uso desse sufixo pode expressar uma atitude ora positiva, ora negativa do falante, dependendo dos aspectos linguísticos e situacionais.

\subsubsection{Diminutivo -inho 3}

O sufixo -inho3, por sua vez, apresenta um valor pragmático bastante parecido com o do sufixo -inho2. Para o sufixo -inho2, a avaliação é direcionada à entidade própria; no entanto, para o sufixo -inho3, a avaliação (ironia, polidez, mitigação etc.) é direcionada ou ao ouvinte a 
quem se concerne a entidade referida, ou à situação na qual o falante, o ouvinte e a entidade são envolvidos. De forma geral, a atitude expressa pelo falante via o sufixo -inhoz é para o ouvinte ou a situação comunicativa, em vez da entidade envolvida. Quanto à restrição de categorias de base (substantivo e adjetivo) para as quais o sufixo -inho 1 é aplicado, não há também essa restrição para o sufixo -inho3. Cabe lembrar que o valor semântico será também muito reduzido para a tradução de uma entidade dada, na medida em que é valorizado o aspecto pragmático, como para o sufixo -inhoz e para o sufixo -inho3. Os Quadros 14 e 15 mostram as dimensões pragmáticas de ironia e de polidez das ocorrências de diminutivos no filme Central do Brasil, respectivamente.

Quadro 14 - Diminutivos que indicam ironia

\begin{tabular}{|c|c|c|c|}
\hline \multicolumn{2}{|l|}{ Tempo } & Português & \multirow{2}{*}{$\begin{array}{c}\text { Inglês } \\
\text {-He's too old to be adopted, Dora! }\end{array}$} \\
\hline $\begin{array}{l}\text { 16. } \quad 00: 30: 55,306 \\
00: 30: 58,275 \\
\end{array}$ & & $\begin{array}{l}\text {-Ele é grandinho demais para ser } \\
\text { adotado, Dora. }\end{array}$ & \\
\hline $\begin{array}{l}\text { 17. } 00: 40: 14,264 \\
00: 40: 18,223\end{array}$ & $-->$ & -Aquele carinha ali, de barba. & $-T h a$ \\
\hline $\begin{array}{l}\text { 18. } \quad 00: 53: 40,270 \\
00: 53: 44,229\end{array}$ & $-->$ & $\begin{array}{l}\text {-Este é pequenininho. Eu quero um } \\
\text { grandão. Turbo. }\end{array}$ & 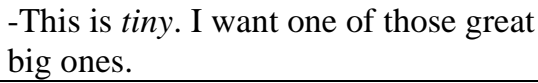 \\
\hline $\begin{array}{l}19 . \quad 00: 56: 21,230 \\
00: 56: 26,190\end{array}$ & $-->$ & $\begin{array}{l}\text {-Sabia que lá no Rio todas as mulheres } \\
\text { transam antes de casar? Todinhas. }\end{array}$ & $\begin{array}{l}\text {-Did you know that, in Rio, all women } \\
\text { have sex before they get married? All } \\
\text { of them. }\end{array}$ \\
\hline $\begin{array}{l}20 . \quad 01: 10: 21,225 \\
01: 10: 28,234\end{array}$ & $-->$ & $\begin{array}{l}\text {-Mas eu vou...dizer uma coisa pra } \\
\text { senhora, ele bebeu a casa todinha na } \\
\text { venda. }\end{array}$ & $\begin{array}{l}\text {-When he got the money, he drank it } \\
\text { all away in the bar on the corner. }\end{array}$ \\
\hline $\begin{array}{l}21 . \quad 01: 25: 42,256 \\
01: 25: 46,215\end{array}$ & $-->$ & $\begin{array}{l}\text {-Como é que eu posso esquecer uma } \\
\text { mocinha assim jeitosinha como você? }\end{array}$ & $\begin{array}{l}\text {-How could I forget such a lovely } \\
\text { specimen as you? }\end{array}$ \\
\hline $\begin{array}{l}22 . \quad 01: 43: 22,24 \\
01: 43: 27,209 \\
\end{array}$ & $-->$ & $\begin{array}{l}\text {-Ele deixou eu, uma menininha, dava o } \\
\text { apito do trem a viagem inteira. }\end{array}$ & $\begin{array}{l}\text {-he'd let me-a girl-blow the whistle } \\
\text { all the way! }\end{array}$ \\
\hline
\end{tabular}

Fonte: elaboração própria

No Quadro 14, todos os diminutivos estão com um tom irônico em relação ao que está sendo referido pelo falante. Para traduzir os dimunutivos "grandinho" e "pequenininho" que estão com esse tom, o tradutor utilizou as traduções too old e tiny respectivamente, como mostram os exemplos 16 e 18. Essas traduções são válidas: por exemplo, tiny no exemplo 18 pode indicar que o caminhão é pequeno demais e que não vale a pena dirigir. No entanto, esse tom irônico pode ter causado dificuldade para o tradutor, o que pode tê-lo levado a optar pela não tradução do diminutivo, mantendo um tom neutro ao preferir usar, por exemplo, "That man", "All of them", "specimen" e "a girl", em inglês, como traduções para "carinha", "Todinhas", "mocinha assim jeitosinha" e "menininha", nos exemplos 17, 19, 21 e 22 respectivamente. 
Quadro 15 - Diminutivos que indicam polidez

\begin{tabular}{|c|c|c|c|}
\hline \multicolumn{2}{|l|}{ Tempo } & Português & \\
\hline $\begin{array}{l}23 . \quad 00: 32: 59,297 \\
00: 33: 04,200\end{array}$ & $-->$ & $\begin{array}{l}\text {-Um minutinho, vou conversar com meu } \\
\text { sócio. Mostrar para ele. }\end{array}$ & $\begin{array}{l}\text {-Well, wait here } a m \\
\text { show the photos to my }\end{array}$ \\
\hline $\begin{array}{l}24 . \quad 00: 53: 46,276 \\
00: 53: 51,236\end{array}$ & & $\begin{array}{l}\text {-Dava pra botar o menino um } \\
\text { pouquinho no volante. Dava? }\end{array}$ & $\begin{array}{l}\text { nk you could let him take } \\
\text { st for a bit? }\end{array}$ \\
\hline $\begin{array}{l}25 . \quad 01: 25: 42,256 \\
01: 25: 46,215\end{array}$ & & $\begin{array}{l}\text {-Como é que eu posso esquecer uma } \\
\text { mocinha assim jeitosinha como você? }\end{array}$ & $\begin{array}{l}\text {-How could I forget such a lovely } \\
\text { specimen as you? }\end{array}$ \\
\hline
\end{tabular}

Fonte: elaboração própria.

No Quadro 15, os diminutivos adverbiais de tempo "minutinho" e "pouquinho" dos exemplos 23 e 24 aparentemente são os mais fáceis de serem traduzidos para inglês - "wait here a moment" e "just for a bit" -, na medida em que ambas as línguas mostram certa atitude de polidez com o uso dos adverbiais de tempo, como "momentinho", just a second etc., além daqueles nos exemplos 23 e 24. Todavia, para fazer uma afirmação dessas, é preciso recorrer a corpora.

Vale observar os dois diminutivos "jeitosinha" nos exemplos 21 e 25, ambos na dimensão pragmática de avaliação do falante em relação ao ouvinte. No filme, a protagonista, Dora, conta ao protagonista, o menino Josué, o que seu pai falou quando ela foi encontrá-lo: “Como é que eu posso esquecer uma mocinha assim jeitosinha como você?”. No exemplo 25, como não foi mostrada a cena entre a Dora e o pai, pode-se imaginar que o pai pode ter falado com um tom polido com ela, ainda que, obviamente, não se lembrasse dela. Porém, no exemplo 21, pode-se constatar que o tom já é diferente quando Dora falou "jeitosinha" com Josué, que é irônico, cheio de desprezo, desespero por ter sido esquecida pelo próprio pai.

A partir da análise realizada, pode-se perceber que o valor semântico é relativamente fácil de ser traduzido, comparado com a complexidade do valor pragmático. Analisando-se as estratégias que o tradutor adotou, pode-se perceber que as palavras como "small" e "little" nas traduções "Whenever you want to remember me, take a look at the small picture we took together." e "Just give me a little money to eat." dos exemplos 6 e 2 funcionam bem para traduzir a ideia de tamanho reduzido em "No dia que quiser lembrar de mim, dá uma olhada no retratinho que a gente tirou junto." e a ideia de quantidade reduzida em "Deixa um pouquinho 1 de dinheiro para eu comer.", respectivamente.

Comparando com esses adjetivos de dimensão semântica, o adjetivo ou advérbio de intensificação por vezes poderiam traduzir o tom da dimensão pragmática. Por exemplo, "tiny”

WANG, Chunyuan. Uma análise semântica e pragmática dos diminutivos na legendagem do filme Central do Brasil para o inglês. Belas Infiéis, Brasília, v. 9, n. 4, p. 229-247, jul./set., 2020. e-ISSN: 2316-6614.

DOI: 10.26512/belasinfieis.v9.n4.2020.26465 
e "too", nas traduções "This is tiny. I want one of those great big ones." e "He's too old to be adopted, Dora!” dos exemplos 18 e 16, podem expressar uma ideia irônica nos contextos do filme "Este é pequenininho. Eu quero um grandão. Turbo." e "Ele é grandinho demais para ser adotado, Dora.”, respectivamente. Quanto à tradução do nome próprio diminutivo em português, para chamar alguém com um tom afetivo ou irônico, pode ser considerado o uso do sufixo -ie, segundo Schneider (2003).

\section{Considerações finais}

Este trabalho teve por objetivo discutir e explorar a adequação das estratégias de tradução de diminutivos em português por meio de uma análise das dimensões semântica e pragmática. Nessa análise, pôde-se perceber que nem todos os diminutivos presentes no filme foram traduzidos de maneira adequada, sendo o tom o que parece ter implicado maior dificuldade para o tradutor.

Por exemplo, o diminutivo "filhinho" no exemplo 9, que expressa afetividade do falante, foi traduzido como "son" e o aumentativo "meninão" no exemplo 10, que também expressa 244 esse mesmo estado, foi traduzido como "sonny", que adequadamente satisfaz o sentido de ambas as palavras. Isso pode significar, por um lado, que o tradutor talvez não reconheça o significado pragmático do diminutivo "filhinho" em português; por outro lado, o tradutor talvez possa ter escolhido sem indicar a afetividade para evitar repetição. Portanto, recomenda-se que o estudo de Schneider (2003) seja abordado em aulas práticas de tradução de legendas para os estudantes aprenderem os sufixos diminutivos em inglês que podem ser utilizados para expressar um tom de afetividade.

Outro exemplo mostra que ainda que o tradutor tenha reconhecido o significado pragmático do diminutivo, ele não conseguiu o traduzir. No exemplo 19, a fala "Sabia que lá no Rio todas as mulheres transam antes de casar? Todinhas." caberia certa atitude de desprezo; no entanto, a tradução "Did you know that, in Rio, all women have sex before they get married? All of them." não mostra esse tom. Isso pode significar que o tradutor não pôde traduzir o tom (mesmo que tenha o conhecimento), na medida em que ele precisa seguir as regras de espaço da legendagem.

Além da análise realizada, foram fornecidas sugestões e/ou estratégias de tradução consideradas adequadas. No entanto, a tradução dos diminutivos em português para o inglês requer não apenas que o tradutor tenha conhecimento de diminutivos nessas línguas, mas também que saiba utilizar outras estratégias para expressar o tom envolvido além do significado 
semântico. No caso específico da tradução da legendagem, a ausência de espaço suficiente para indicar a dimensão pragmática parece dificultar ainda mais o trabalho do tradutor. Além da questão de espaço, a escolha final (legenda) pode ter sido interferida por outros agentes, apesar de o tradutor ter todo o conhecimento de tradução dos diminutivos.

No final, vale ressaltar que, no âmbito de tradução de diminutivos do português para inglês na legendagem, muitos estudos ainda precisam ser feitos, a fim de, por um lado, encontrar simetrias completas possíveis das duas dimensões, a semântica e a pragmática, para as categorias de diminutivos possíveis e, por outro, resumir as estratégias de tradução que não sejam as de uso de diminutivos.

\section{Agradecimentos}

Este trabalho foi realizado com apoio da Coordenação de Aperfeiçoamento de Pessoal Nível Superior - Brasil (CAPES) - Código de Financiamento 001. Agradeço ao meu orientador de especialização, Gilson André França de Mattos, e à minha orientadora atual, Ana Maria Tramunt Ibaños, por terem dado sugestões. Agradeço especialmente aos/às dois/duas pareceristas anônimos/as da revista, cujas contribuições foram valiosas para a versão final deste artigo. Os possíveis erros que permanecem neste trabalho são de responsabilidade minha.

\section{REFERÊNCIAS}

ABREU, Thais Holanda de. Estudo das formas aumentativas e diminutivas em Português Arcaico. 2012. 211 f. Dissertação (Mestrado em Linguística) - Universidade Estadual Paulista, Araraquara, 2012.

ADAMS, Valerie. Complex words in English. Harlow: Pearson Education, 2001.

ALVES, Elisabeth. O diminutivo no português do Brasil: funcionalidade e Tipologia. Estudos Lingüísticos, Brasília, v. XXXV, p. 694-701, 2006. Disponível em:

http://www.gel.hospedagemdesites.ws/estudoslinguisticos/edicoesanteriores/4publicaestudos-2006/sistema06/885.pdf. Acesso em: 17 fev. 2020.

ARMELIN, Paula Roberta Gabbai. Sobre a interação entre as marcas de diminutivo e aumentativo no português brasileiro. ReVEL, edição especial n. 5, paginação irregular, 2011. Disponível em: www.revel.inf.br. Acesso em: 17 fev. 2020.

BARBOSA, Maria Fernanda Moreira. A alternância do diminutivo -inho/-zinho no português brasileiro: uma abordagem pela Fonologia de Uso. 2012. 171 f. Dissertação (Mestrado em Linguística) - Universidade Federal do Rio de Janeiro, Rio de Janeiro, 2012.

BASÍLIO, Margarida M. P. Formação e classes de palavras no português do Brasil. São Paulo: Contexto, 2004.

BASSO, Renato Miguel; PETRY, Michele Bete. Uma análise dos diminutivos na tradução da história em quadrinhos Tintin en Amérique para o português brasileiro. Revista do GEL, São

WANG, Chunyuan. Uma análise semântica e pragmática dos diminutivos na legendagem do filme Central do Brasil para o inglês. Belas Infiéis, Brasília, v. 9, n. 4, p. 229-247, jul./set., 2020. e-ISSN: 2316-6614.

DOI: 10.26512/belasinfieis.v9.n4.2020.26465 
Paulo, n. 2, v. 10, p. 8-41, 2013. Disponível em: https://revistas.gel.org.br/rg. Acesso em: 17 fev. 2020.

BYBEE, Joan L. Morphology: the relations between meaning and form.

Amsterdam/Philadelphia: John Benjamins, 1985. doi: https://doi.org/10.1075/tsl.9

CHAVES, Anna Libia Araujo. O sufixo -inho nas entrevistas VALPB: uma análise semânticodiscursiva. 2006. 93 f. Dissertação (Mestrado em Letras) - Universidade Federal da Paraíba, João Pessoa, 2006.

DRESSLER, Wolfgang U.; BARBARESI, Lavinia Merlini. Morphopragmatics: Diminutives and Intensifiers in Italian, German, and Other Languages. Berlin, New York: Mouton de Gruyter, 1994. https://doi.org/10.1515/9783110877052

ROCHA, Luiz Carlos de Assis. Estruturas morfológicas do português. Belo Horizonte: Editora UFMG, 2003.

RODRIGUES, Geralda Fátima de Souza. Realizações dos sufixos -(z)inho/-(z)im no português brasileiro dialetal: análise variacionista. 2015. $195 \mathrm{f}$. Tese (Doutorado em Estudos Linguísticos) - Universidade Federal de Minas Gerais, Belo Horizonte, 2015.

SANTANA, Messias dos Santos. O sufixo diminutivo em português: forma, funcionamento e significação - do século XIII ao XX. 2017. 912 f. Tese (Doutorado em Letras) - Universidade de São Paulo, São Paulo, 2017.

SANTOS, Mário Augusto da Silva. O traduzível e intraduzível: o caso dos sufixos aumentativos e diminutivos. Rev. de Letras, Fortaleza, n. 23, v. 1/2, p. 71-76, jan./dez. 2001. Disponível em: http://www.periodicos.ufc.br/revletras/index. Acesso em: 17 fev. 2020.

SCHNEIDER, Klaus P. Diminutives in English. Tübingen: Max Niemeyer Verlag, 2003. https://doi.org/10.1515/9783110929553

SUBSCENE. Legenda do filme Central do Brasil. Disponível em: https://subscene.com/subtitles/central-station-central-do-brasil Acesso em: 17 fev. 2020.

TURUNEN, Virpi Johanna. Diminutivo em português e em francês: um pouquinho é un petit peu. In: MAGALHÃES, José Sueli de; TRAVAGLIA, Luiz Carlos (Org). Múltiplas Perspectivas em Linguística. Uberlândia: Edufu, 2006. p. 3008-3016

TURUNEN, Virpi Johanna. Sobre a descrição das dimensões semânticas e pragmáticas do diminutivo em português. Revista Escrita, Rio de Janeiro, n. 9, p. 1-13, nov. 2008. Disponível em: https://www.maxwell.vrac.puc-rio.br/12478/12478.PDF. Acesso em: 17 fev. 2020. https://doi.org/10.17771/PUCRio.escrita.12478

TURUNEN, Virpi Johanna. A reversão da relevância: aspectos semânticos e pragmáticos de formações diminutivas no português do Brasil. 2009. 194 f. Tese (Doutorado em Linguística) - Pontifícia Universidade Católica do Rio de Janeiro, Rio de Janeiro, 2009. 
${ }^{1}$ Essas traduções são oriundas do site profissional de legendagem Subscene.

\section{NOTA DO AUTOR}

Chunyuan WANG - Mestrando em Letras na Pontifícia Universidade Católica do Rio Grande do Sul. Especialista em Estudos da Tradução (2018) pela mesma instituição. Graduado em Engenharia Mecânica e Automação (2013) pela Universidade de Ciências e Tecnologias de Guangxi, China. Pontifícia Universidade Católica do Rio Grande do Sul, Escola de Humanidades, Programa de Pós-Graduação em Letras. Porto Alegre, Rio Grande do Sul, Brasil. ORCID: https://orcid.org/0000-0002-2875-3069

Currículo acadêmico: http://lattes.cnpq.br/8666176286049111

E-mail: chunyuan.wang@edu.pucrs.br 